\title{
Separation of airway and tissue properties by transfer respiratory impedance and thoracic gas volume in reversible airway obstruction
}

\author{
F. Marchal*, N. Bouaziz*, C. Baeyert*, C. Gallina**, C. Duvivier**, R. Peslin**
}

Separation of airway and tissue properties by transfer respiratory impedance and thoracic gas volume in reversible airway obstruction. F. Marchal, N. Bouaziz, C. Baeyert, C. Gallina, C. Duvivier, R. Peslin. CERS Journals Ltd 1996.

ABSTRACT: The aim of this study was to establish the ability to estimate separate airway and tissue properties from transfer respiratory impedance $\left(Z_{r s, t r}\right)$ data in the presence of airway obstruction.

Zrs,tr, thoracic gas volume (TGV) and airway resistance (Raw,pleth) were measured in the presence of obstruction and after use of a bronchodilator (BD) in 13 normal or asymptomatic asthmatic adults and 28 children with symptomatic asthma. An analytical approach was used to solve the equations of a simplified variant of DuBois' model, including airway resistance $\left(R_{\text {aw* }}\right.$ ) and inertance (Iaw), tissue compliance $(C \mathrm{t})$ and resistance $(R \mathrm{t})$ and pulmonary gas compliance $\left(C_{\mathrm{g}}\right)$.

The equations of the model could not be reliably solved in four children before BD. Mean $R$ aw,pleth was not different from mean $R$ aw* in adults before (mean \pm SEM) $\left(3.4 \pm 0.5\right.$ vs $\left.3.1 \pm 0.3 \mathrm{hPa} \cdot \mathrm{s}^{\cdot} \mathrm{L}^{-1}\right)$ or after BD $\left(1.4 \pm 0.2\right.$ vs $\left.1.8 \pm 0.2 \mathrm{hPa} \cdot \mathrm{S}^{\circ} \cdot \mathrm{L}^{-1}\right)$, or in children after $\mathrm{BD}\left(2.9 \pm 0.3\right.$ vs $3.2 \pm 0.2 \mathrm{hPa} \cdot \mathrm{s} \cdot \mathrm{L}^{-1}$, respectively). In children before $\mathrm{BD}$, $R$ aw* was significantly underestimated compared with $R$ aw,pleth $(3.8 \pm 0.4$ vs $5.4 \pm 0.6$ $\left.h P a \cdot s \cdot L^{-1}\right)$. Overall, a significant positive correlation was found between the difference [Raw,pleth - $R$ aw*] and $R$ aw,pleth $(\mathrm{r}=0.82)$. In adults, BD induced a decrease in $R_{\text {aw* }}$ and $R \mathrm{t}$, an increase in $C \mathrm{t}$, and no change in $I_{\mathrm{aw}}$. In children after $\mathrm{BD}$, there was no significant change in $R$ aw* or $C t$, whilst $R \mathrm{t}$ decreased and $I$ aw increased.

Taking $R$ aw,pleth as the gold standard, it is concluded that coherent estimation of parameters of DuBois' model may be obtained from combined $Z_{\text {rs, tr }}$ and TGV measurements in normal subjects and moderately obstructed adults, but not in children with significant airway obstruction. This seems to be due to the systematic underestimation of Raw*.

Eur Respir J., 1996, 9, 253-261.

Respiratory input impedance $\left(Z_{r s}\right.$,in) measured by the forced oscillation technique is becoming increasingly popular in lung function testing, and provides a convenient, noninvasive estimation of respiratory system resistive and reactive properties. Another interesting approach is to obtain the transfer impedance of the respiratory system (Zrs,tr) by varying pressure at the chest wall and measuring flow at the mouth. The advantage of this technique is twofold. Firstly, pressure variations in the pneumotachograph are small and the accuracy of flow measurement at high frequency does not critically depend on the symmetry of the flow channel. This is particularly important when large resistances are to be measured [1], which is the case of children with airway obstruction. Secondly, Zrs,tr is significantly influenced by pulmonary gas compressibility $(C \mathrm{~g})$ described in DuBois' model [2].

The parameters of airway and tissue impedance were estimated from $Z$ rs,tr in normal adult humans, using $C \mathrm{~g}$ value provided by thoracic gas volume (TGV) measurement [3]. With comparative measurements of $\mathrm{Zrs}$,in and
*Laboratoire d'Explorations Fonctionnelles Pédiatriques, Hôpital d'Enfants, Vandœuvre lès Nancy, France. **Unité 14 INSERM de Physiopathologie Respiratoire, Vandœuvre lès Nancy, France.

Correspondence: F. Marchal

Laboratoire de Physiologie

Faculté de Médecine de Nancy

Avenue de Forêt de Haye

BP184 54505 Vandœuvre lès Nancy

France

Keywords: Airway obstruction airway resistance

bronchodilator

children

transfer respiratory impedance

Received: October 281994

Accepted after revision October 201995
Zrs,tr it was found that the second, but not the first, approach could provide a correct estimation of airway and tissue parameters [4]. It was also shown in healthy dogs and humans that the spectrum of excitation frequency should include the antiresonance peak for optimal parameter estimation $[4,5]$. The sensitivity functions of the model are highly dependent on the relative values of these parameters $[5,6]$, which are subjected to substantial between-species variation, and, within a given species, to the effect of growth and respiratory disease. An important practical limitation to the use of high frequency is the parallel arrangement of upper airway wall and pneumotachograph, which is responsible for an error in the measurement of flow that increases with increasing frequency. Moreover in a recent study, we found that coherent estimation of airway and tissue parameters was possible below $40 \mathrm{~Hz}$ in infants, in the absence of overt airway obstruction [7].

An important and practical indication to the adequate description of the mechanical properties of the respiratory system by DuBois' model is the demonstration 
that the parameters are correctly estimated when one compartment (e.g. airway impedance) is changed. The aim of this study was, thus, to compare airway resistance estimated after DuBois' model with that measured by plethysmography in patients with airway obstruction and after reversal by use of a bronchodilator.

\section{Material and methods}

\section{Subjects}

Forty one subjects were studied: 13 adults aged 22-55 yrs (mean \pm SEM $33 \pm 3 \mathrm{yrs}$ ) and 28 children aged 10-19 yrs $(13 \pm 1 \mathrm{yrs})$. Nine adults were normal subjects, members of the laboratory staff, and four were former asthmatics without history of asthma attack in the past year, and receiving no medication. The 28 children were all asthmatics, and their baseline forced expiratory volume in one second (FEV1) was $<70 \%$ predicted in 10 , and $>70 \%$ pred in 18 . The study was approved by the Regional Committee on Human Subjects Experimentation.

\section{Protocol}

Airway challenge. Eight normal adults, and 12 asthmatic children with FEV1 $>70 \%$ pred were challenged with methacholine. Methacholine chloride (Pharmacie centrale des Hôpitaux de Paris) was administered in cumulative doses, from 100 to $1,200 \mu \mathrm{g}$, with metered-dose inhaler and spacer device. The six other children with FEV1 $>70 \%$ pred were challenged with allergenic extracts of house dust mites (Alyostal, Stallergenes, Pasteur), from a solution of $0.5-12$ IR, using a Wright nebulizer [8].

Reversibility of airway obstruction. Salbutamol (300 $\mu \mathrm{g})$ was given to one normal adult, to four adults with history of asthma and to the 10 children with baseline FEV1 $<70 \%$ pred. Bronchodual $(150 \mu \mathrm{g}$ fenoterol and $60 \mu \mathrm{g}$ ipratropium bromide) was given to all subjects after provocation. Both bronchodilators were administered with metered-dose inhaler and spacer device.

FEV1 was first measured to detect the presence of airway obstruction. In the presence of obstruction, the measurements of Zrs,tr, TGV and airway resistance (Raw,pleth) were performed and repeated after use of the bronchodilator. Without evidence of airway obstruction, methacholine was administered, until 15\% decrease in FEV1 was observed, or the maximum dose was attained. The measurements of $Z$ rs,tr, TGV and Raw,pleth were then obtained, and repeated, as above, after use of the bronchodilator.

\section{Measurements}

FEV1 was measured using a spirometer (Spiromatic, Gauthier, France). The subjects were trained to perform a forced vital capacity (FVC) manoeuvre, and the best (largest peak flow and largest FVC) of three reproducible curves was retained.
Thoracic gas volume (TGV) and airway resistance (Raw,pleth) were measured in a pressure type $890 \mathrm{~L}$ body plethysmograph (Siregnost 91S, Siemens, Erlangen, Germany). The subject was trained to make respiratory efforts at about $1-2 \mathrm{~Hz}$ for $3-5 \mathrm{~s}$. TGV was measured from the box volume-airway pressure relationship obtained during airway occlusion at end-expiration. Both signals were analogue-to-digital (A/D) converted, and the linear correlation between pressure and volume was calculated by the least square method, after correction for the drift of the box volume signal [9]. Raw,pleth was measured at about the same breathing frequency, whilst the subject was panting through a dead space. The relationship between box pressure and airway flow was calculated using similar algorithms.

The set-up for $\mathrm{Zrs}$,tr measurement is described in figure 1a. The subject was enclosed in a wooden chamber up to his neck. Pressure was varied around the chest by

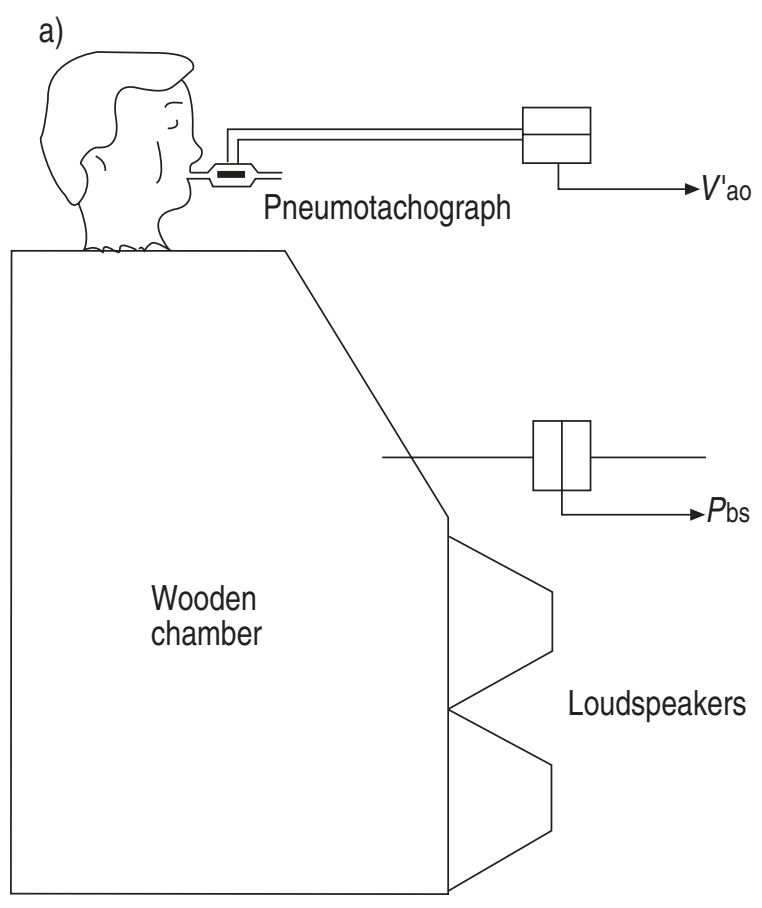

b)

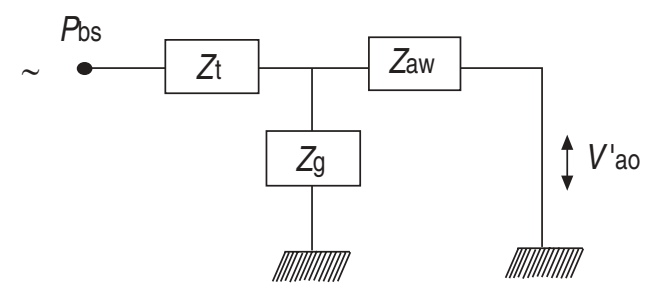

Fig. 1. - a) Experimental set-up for measuring transfer respiratory impedance (Zrs,tr). A pair of loudspeakers is used to oscillate pressure around the chest of the subject seated in a wooden chamber $(\mathrm{Pbs})$. A partition is loosely fitted around the neck, so that both the pneumotachograph opening and the upper airway wall are exposed to barometric pressure. $Z r s$,tr is then obtained from the Fourier transforms of $P$ bs and flow at the mouth $\left(V^{\prime}\right.$ ao). b) Diagramatic representation of DuBois' model, with airway (Zaw) and tissue impedance $(Z \mathrm{t})$. The impedance of the alveolar gas $(\mathrm{Zg})$, represented by its compressibility, makes it possible to separate the mechanical properties of the airways, and lung/chest wall tissues. 
two $45 \mathrm{~W}$ loudspeakers connected to the chamber and driven by a pseudorandom signal containing all harmonics of $2 \mathrm{~Hz}$ from 6 to $32 \mathrm{~Hz}$, generated by a microcomputer at $512 \mathrm{~Hz}, \mathrm{D} / \mathrm{A}$ converted and amplified. Airway flow was measured with a Fleisch No. 2 pneumotachograph connected to a differential pressure transducer (Honeywell $\pm 35 \mathrm{cmH}_{2} \mathrm{O}$ ), and the pressure at the chest was measured with an identical transducer, matched to the first within $1 \%$ of amplitude and $2^{\circ}$ of phase up to $32 \mathrm{~Hz}$. The common mode rejection ratio of the flow channel was $60 \mathrm{~dB}$ at $32 \mathrm{~Hz}$. The pneumotachograph was calibrated by the integral method, and the pressure channel with a precision fluid-manometer. The accuracy of the apparatus was checked daily with a physical analogue, and the whole calibration procedure was repeated whenever the results were found to deviate by more than $5 \%$ from the expected value.

Pressure and flow were A/D converted at $128 \mathrm{~Hz}$, for a $16 \mathrm{~s}$ data acquisition period. The fast Fourier transforms of pressure and flow were calculated using seven data blocks of $4 \mathrm{~s}$ with $50 \%$ overlapping. Respiratory resistance $(R \mathrm{rs})$ and reactance $(X \mathrm{rs})$ were then computed from the in-phase and out-of-phase components of pressure and flow, together with the coherence function between these signals $\left(\gamma^{2}\right)$, an index of signal-to-noise ratio. Data with $\gamma^{2}$ lower than 0.95 were not retained for analysis. At least three data acquisition periods were averaged.

\section{Data analysis}

Third order model. This model features tissue $(\mathrm{Zt})$ and airway impedances (Zaw) separated by the impedance of the alveolar gas $(\mathrm{Zg})$, as described in figure $1 \mathrm{~b}$. For a pressure input at the chest, flow measurement at the mouth, and parallel arrangement between airway and pulmonary gas, Zrs,tr may be written:

$$
Z \mathrm{rs}, \mathrm{tr}=\mathrm{Zt}+\mathrm{Zaw}_{\mathrm{aw}} \mathrm{Zaw} \cdot \mathrm{Zt} / \mathrm{Zg}
$$

Each impedance is characterized by one or more resistive, inertive and/or elastic elements, and $\mathrm{Zaw}, \mathrm{Zt}$ and $\mathrm{Zg}$ may, thus, be written:

$$
\begin{gathered}
Z_{\text {aw }}=R \mathrm{aw}+\mathrm{j} I \mathrm{aw} \cdot \omega \\
Z_{\mathrm{g}}=-\mathrm{j} / C_{\mathrm{g}} \cdot \omega \\
\mathrm{Zt}=R \mathrm{t}-\mathrm{j} / C_{\mathrm{t}} \cdot \omega
\end{gathered}
$$

where $R$ aw and Iaw are airway resistance and inertance, $R \mathrm{t}$ and $C \mathrm{t}$ are tissue resistance and compliance, and $C_{\mathrm{g}}$ is the gas compressibility or compliance, $\omega$ is angular frequency $(2 \pi f)$, and $\mathrm{j}=\sqrt{ }-1$ is the unit of imaginary numbers. Note also that the model is simplified by neglecting tissue inertance, which has been shown not to significantly affect the frequency response of Zrs,tr up to $30 \mathrm{~Hz}[3]$.

Determination of the coefficients of Zrs,tr. Zrs,tr is characterized by a decrease of the resistance with frequency, which may become negative at high frequencies, and an increase of the reactance, which is negative below and positive above resonant frequency. When solving for the real and imaginary part of Equation (1), using the five elements described in Equations (2) to (4), it may be shown that both resistance and reactance may be written as functions of angular frequency:

$$
\begin{aligned}
& R \mathrm{rs}=\mathrm{m} 1-\mathrm{m} 3 \cdot \omega 2 \\
& X \mathrm{rs}=-\mathrm{m} 0 / \omega+\mathrm{m} 2 \cdot \omega
\end{aligned}
$$

where the coefficients $\mathrm{m} 0$ to $\mathrm{m} 3$ have the following meaning:

$$
\begin{gathered}
\mathrm{m} 0=1 / C \mathrm{t} \\
\mathrm{m} 1=R \mathrm{t}+R \mathrm{aw}(1+C \mathrm{~g} / C \mathrm{t}) \\
\mathrm{m} 2=I \mathrm{aw}(1+C \mathrm{~g} / C \mathrm{t})+R \mathrm{aw} \cdot R \mathrm{t} \cdot C \mathrm{~g} \\
\mathrm{~m} 3=I \mathrm{aw} \cdot R \mathrm{t} \cdot C \mathrm{~g}
\end{gathered}
$$

$\mathrm{m} 0$ to $\mathrm{m} 3$ were calculated by least square regression analysis of $R \mathrm{rs}$ and of $X \mathrm{rs} \cdot \omega$ vs $\omega^{2}$ using Equations (5) and (6).

The goodness of fit of the data to the model was evaluated by the residual term $(\chi)$ between observed and predicted impedance:

$$
\chi=\sqrt{ }\left\{\left(\sum\left[(R \mathrm{rs}, \mathrm{o}-R \mathrm{rs}, \mathrm{m})^{2}+(X \mathrm{rs}, \mathrm{o}-X \mathrm{rs}, \mathrm{m})^{2}\right]\right) /(2 \mathrm{n}-\mathrm{a})\right\}
$$

where $R \mathrm{rs}, \mathrm{o}, X \mathrm{rs}, \mathrm{o}, R \mathrm{rs}, \mathrm{m}, X \mathrm{rs}, \mathrm{m}$ are the observed and model resistance and reactance, respectively, and $n$ and a the number of frequencies and coefficients, respectively.

The relative distance (d) was then obtained by dividing $\chi$ by the average impedance modulus. $C \mathrm{~g}$ was calculated from TGV measurement as:

$$
C \mathrm{~g}=\left[(\mathrm{TGV}+V \mathrm{~T} / 2) /\left(P \mathrm{~B}-P \mathrm{H}_{2} \mathrm{O}\right)\right]
$$

where $P \mathrm{~B}$ is barometric pressure, $\mathrm{PH}_{2} \mathrm{O}$ alveolar water vapour pressure and $V \mathrm{~T} / 2$ roughly accounts for the average contribution of tidal volume to gas compressibility in spontaneously breathing subjects.

Knowing $C$ g, the other coefficients may be obtained by solving Equations (7) to (10) for $R$ t, which yields the following third degree equation:

$$
R \mathrm{t}^{3}-\mathrm{m} 1 \cdot R \mathrm{t}^{2}+(K \cdot \mathrm{m} 2 / C \mathrm{~g}) \cdot R \mathrm{t}-\mathrm{m} 3 \cdot \mathrm{K}^{2} / C_{\mathrm{g}^{2}}=0
$$

where $K=1+\mathrm{m} 0 \cdot C \mathrm{~g}$. The other coefficients may then be easily computed from Equations (8) to (10). A practical problem is that, in some instances, Equation (13) may have three real roots, so that the analysis provides three sets of coefficients. This was the case in four out of a total of 82 determinations. As discussed later on, this happens when airway resistance is increased. One of the solutions then provides an unrealistically high value for $R \mathrm{t}$ and low value for Iaw, and may readily be excluded. The two other solutions, however, are usually realistic, and there is little ground on which to make a choice between them. We therefore discarded the corresponding measurements (see Discussion). 


\section{Statistics}

Analysis of variance for repeated measures and least square linear regression were used as necessary. The agreement between $R$ aw,pleth and the value of airway resistance obtained derived from model $\left(R_{a w} *\right)$ was also assessed by plotting the difference [Raw,pleth-Raw*] with the reference measurement (i.e. Raw,pleth), as suggested by Bland and Altman [10]. The normalized residuals of respiratory resistance and reactance were compared to zero using one group t-test. Statistical significance was considered at p-values less than 0.05. Data are expressed as mean \pm SEM, unless otherwise indicated.

\section{Results}

\section{Evaluation of the reversibility of airway obstruction}

The mean data on FEV1 and TGV presented in table 1 are for adults and children. In both groups, bronchodilation is associated with a significant increase in $\mathrm{FEV} 1$, but the decrease in TGV observed in both groups is significant only in children, probably because of the larger sample size. In both groups, we also found a significant decrease in Raw,pleth, as shown in table 2.

\section{Frequency response of Zrs,tr}

An example of frequency response of Zrs,tr in an asymptomatic asthmatic before and after bronchodilator is illustrated in figure 2. It can be seen that the general

Table 1. - FEV1 and TGV before and after bronchodilation (BD)

\begin{tabular}{lcccc}
\hline & \multicolumn{2}{c}{ Children } & \multicolumn{2}{c}{ Adults } \\
& FEV1 & TGV & FEV1 & TGV \\
& L & L & L & L \\
\hline PreBD & $2.1 \pm 0.2$ & $1.92 \pm 0.11$ & $3.3 \pm 0.2$ & $2.95 \pm 0.23$ \\
PostBD & $2.5 \pm 0.2 *$ & $1.77 \pm 0.10^{*}$ & $3.7 \pm 0.3 *$ & $2.81 \pm 0.18$ \\
\hline
\end{tabular}

Values are presented as mean \pm SEM. FEV1: forced expiratory volume in one second; TGV: thoracic gas volume. *: $\mathrm{p}<0.001$ vs preBD.
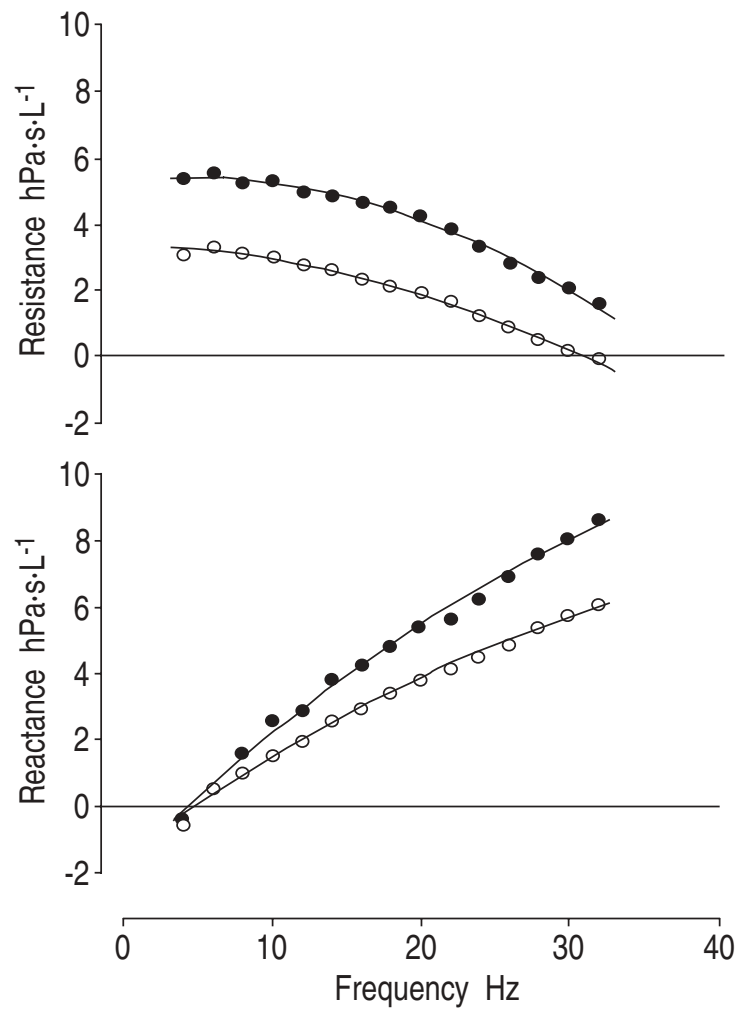

Fig. 2. - Zrs,tr before (- - ) and after (- - - ) bronchodilation in an asymptomic asthmatic adult. Resistance and reactance are plotted against frequency. It can be seen that the fitting of the model curve to the data is satisfactory in both cases. In this example, Raw* (airway resistance extracted from the model) is $4.0 \mathrm{hPa} \cdot \mathrm{s} \cdot \mathrm{L}^{-1}$ before and $1.9 \mathrm{hPa} \cdot \mathrm{s} \cdot \mathrm{L}^{-1}$ after salbutamol, and both values compare well with $R$ aw, pleth $\left(3.8 \mathrm{hPa} \cdot \mathrm{s} \cdot \mathrm{L}^{-1}\right.$ before and $1.8 \mathrm{hPa} \cdot \mathrm{s} \cdot \mathrm{L}^{-1}$ after salbutamol). $\mathrm{Zrs}$,tr: transfer respiratory impedance; Raw,pleth: plethysmographic airway resistance.

frequency response described in a normal adult, with negative frequency dependence of resistance, is observed in this subject, both before and after bronchodilator. The fit of the model curve to the data appears satisfactory in both cases, and the quadratic error is $3.3 \%$ before and $2.5 \%$ after bronchodilator. As shown in table 2, the distance is not significantly different before and after bronchodilator, in adult or children. The fitting errors were also calculated at each frequency as the difference between observed and model values of $R$ rs and $X \mathrm{rs}$, normalized for the impedance modulus. Figure 3 shows that, in both conditions, the residual of resistance is about

Table 2. - Plethysmographic airway resistance (Raw,pleth), and model estimated airway resistance (Raw*), airway inertance (law), tissue resistance $(R \mathrm{t})$ and compliance $(C \mathrm{t})$, and distance to the model $(\mathrm{d})$ before and after bronchodilation (BD)

\begin{tabular}{|c|c|c|c|c|c|c|}
\hline & $\begin{array}{l}\text { Raw,pleth } \\
\mathrm{hPa} \cdot \mathrm{s} \cdot \mathrm{L}^{-1}\end{array}$ & $\begin{array}{c}R \mathrm{aw}^{*} \\
\mathrm{hPa} \cdot \mathrm{s} \cdot \mathrm{L}^{-1}\end{array}$ & $\begin{array}{c}\text { Iaw } \\
\mathrm{Pa} \cdot \mathrm{s}^{2} \cdot \mathrm{L}^{-1}\end{array}$ & $\begin{array}{c}R \mathrm{t} \\
\mathrm{hPa} \cdot \mathrm{s} \cdot \mathrm{L}^{-1}\end{array}$ & $\begin{array}{c}C \mathrm{t} \\
\mathrm{mL} \cdot \mathrm{hPa}^{-1}\end{array}$ & $\begin{array}{l}\mathrm{d} \\
\%\end{array}$ \\
\hline \multicolumn{7}{|l|}{ Children } \\
\hline PreBD & $5.4 \pm 0.6$ & $3.8 \pm 0.4^{\S}$ & $1.8 \pm 0.2$ & $4.4 \pm 0.9$ & $22.5 \pm 2.8$ & $4.7 \pm 0.2$ \\
\hline PostBD & $2.9 \pm 0.3^{\circ}$ & $3.2 \pm 0.2$ & $2.7 \pm 0.1^{\circ}$ & $1.4 \pm 0.1^{\circ}$ & $24.1 \pm 1.8$ & $5.0 \pm 0.2$ \\
\hline \multicolumn{7}{|l|}{ Adults } \\
\hline PreBD & $3.4 \pm 0.5$ & $3.1 \pm 0.3$ & $1.8 \pm 0.2$ & $1.9 \pm 0.3$ & $27.5 \pm 2.2$ & $4.7 \pm 0.3$ \\
\hline PostBD & $1.4 \pm 0.2^{\circ}$ & $1.8 \pm 0.2^{\circ}$ & $2.0 \pm 0.1$ & $1.3 \pm 0.1^{+}$ & $31.9 \pm 2.5^{\circ}$ & $5.4 \pm 0.4$ \\
\hline
\end{tabular}

Values are presented as mean \pm SEM. \$: $\mathrm{p}<0.05$ vs Raw,pleth; ${ }^{\circ}: \mathrm{p}<0.005$ vs preBD; +: $\mathrm{p}<0.05$ vs preBD. d: distance to the model (calculated from equation 11). 
a)

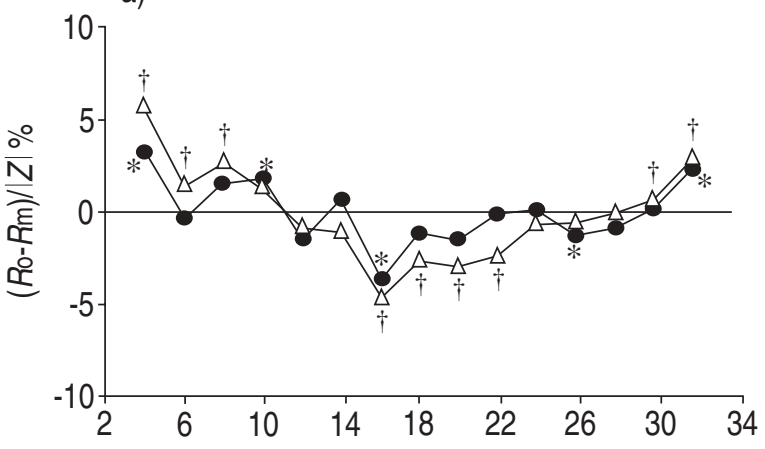

b)

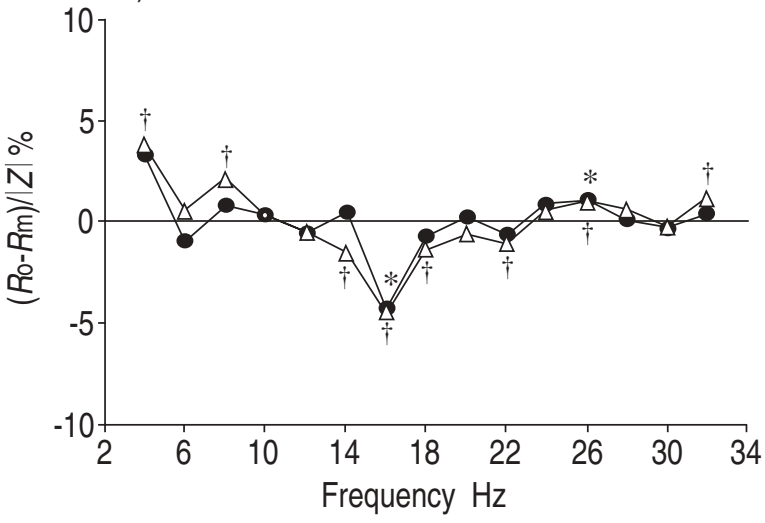

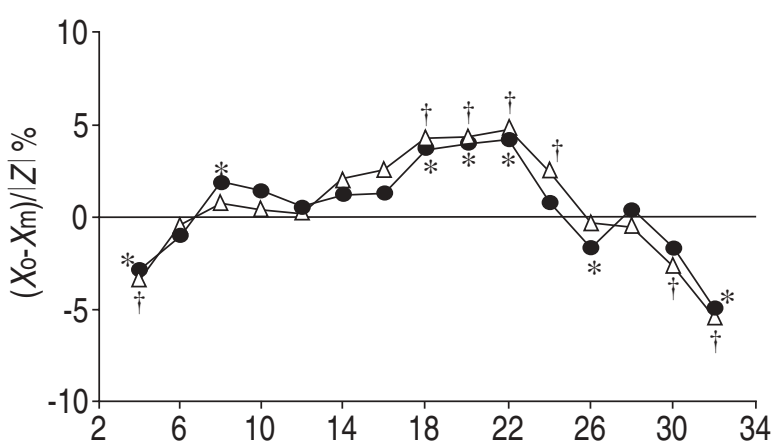

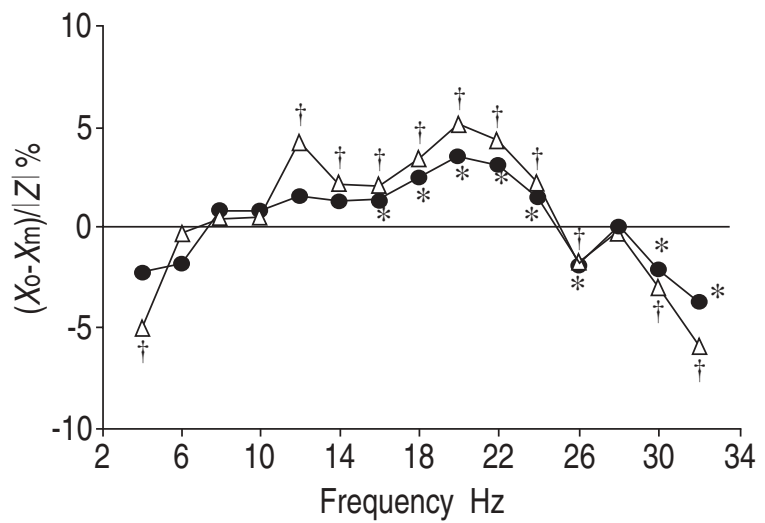

Fig. 3. - Fitting errors calculated at each frequency as the difference between observed (Ro, $\left.X_{\mathrm{o}}\right)$ and model (Rm, $\left.X \mathrm{~m}\right)$ values of $R \mathrm{rs}(\mathrm{left}$ panels) and $X \mathrm{rs}$ (right panels), normalized for the measured impedance modulus $(|Z|)$. a) adults; b) children. In both conditions, the residual of resistance is about $5 \%$ at $4 \mathrm{~Hz}$, decreases to $-5 \%$ at $16 \mathrm{~Hz}$, and then increases again to about $3 \%$ at $32 \mathrm{~Hz}$. The error on reactance shows almost opposite changes: negative at $4 \mathrm{~Hz}$, it increases to about $5 \%$ at $18 \mathrm{~Hz}$, and decreases from 22 to $32 \mathrm{~Hz}$. Adults and children show a similar pattern, and there is no systematic difference between obstruction and bronchodilation. Symbols indicate the values that are significantly different from zero for obstruction $(*)$ and bronchodilatation $(\dagger)$ (standard error not shown for clarity). Rrs: resistance of the respiratory system; Xrs: reactance of the respiratory system. ——: obstruction; $-\Delta-$ : bronchodilation.

$5 \%$ at $4 \mathrm{~Hz}$, decreases to $-5 \%$ at $16 \mathrm{~Hz}$, and then increases again to approximately $3 \%$ at $32 \mathrm{~Hz}$. The error on reactance shows almost opposite changes: negative at 4 $\mathrm{Hz}$, it increases to about $5 \%$ at $18 \mathrm{~Hz}$, and decreases from 22 to $32 \mathrm{~Hz}$. Adults and children show a similar pattern, and there is no systematic difference between obstruction and bronchodilation.

\section{Coefficients of DuBois' model}

The coefficients obtained by solving Equations (7) to (10), using $C$ g calculated from the TGV value, are listed in table 2. Adults show significant reduction in the estimated airway resistance (Raw*) and much less but still significant reduction in tissue resistance, with no change in Iaw. Tissue compliance is also found to increase after bronchodilation. In the children, the findings are markedly different. $R$ aw* and $C$ t are, surprisingly, not changed by use of a bronchodilator but airway inertance increases, whilst tissue resistance decreases significantly after bronchodilation.

\section{Correspondence between Raw,pleth and Raw*}

The agreement between the two estimates of airway resistance was also variable. In adults, $R$ aw* was not significantly different from Raw,pleth, both before and after bronchodilators. In children before bronchodilation, Raw* was significantly lower than Raw,pleth, but the difference was cancelled after bronchodilation (table 2). The correlation observed between the two estimates of $R$ aw was variable in adults and children. $R$ aw* and $R$ aw,pleth were significantly correlated in adults $(\mathrm{r}=0.62)$ as well as in children after bronchodilation $(r=0.52)$, but not in children with airway obstruction. Interestingly, plotting the difference [Raw,pleth - Raw*] against Raw,pleth disclosed a strong positive relationship $(\mathrm{r}=0.82)$. Larger $R$ aw,pleth was associated with larger difference between $R$ aw,pleth and $R$ aw*, i.e. there was a significant underestimation of Raw* in the presence of severe airway obstruction (fig. 4).

There was a significant correlation between the percentage change in Raw,pleth and in $\mathrm{m} 1$ induced by bronchodilation $(\mathrm{r}=0.57 ; \mathrm{p}<0.005)$, as reported in figure 5 . In contrast, there was no significant correlation between $\Delta \%$ Raw,pleth and $\Delta \%$ Raw*. In adults, $\Delta \%$ Raw* $(-39.3 \pm 5.7 \%)$ was smaller than $\Delta \%$ Raw,pleth $(-53.6 \pm 5.3 \%)$ but the difference did not reach statistical significance $(\mathrm{p}=0.06)$. In children, $\Delta \%$ Raw,pleth $(-41.8 \pm 3.7 \%)$ was significantly different from $\Delta \%$ Raw $*(20.9 \pm 27.7 \%$; $\mathrm{p}<0.05)$ which showed very large dispersion, as a result of the underestimation of Raw* in subjects with severe obstruction (fig. 4). 


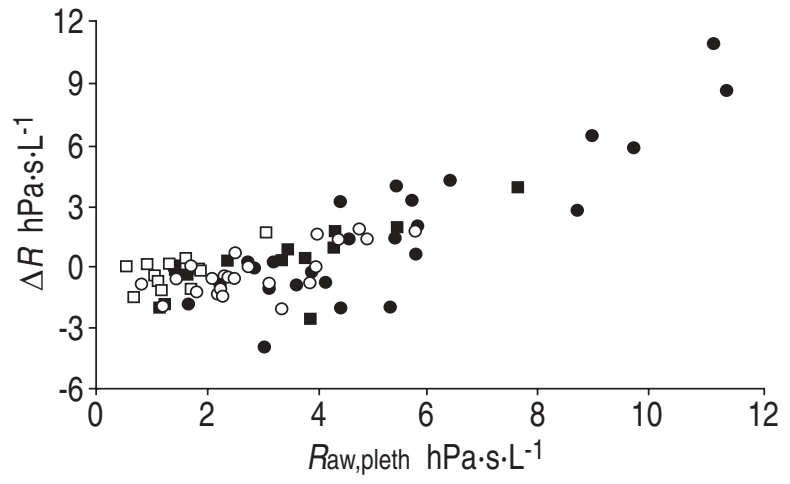

Fig. 4. - Relationship between the difference [Raw,pleth - Raw*] $(\Delta R)$ and Raw,pleth. The underestimation of Raw* is significantly correlated to the magnitude of actual airway resistance $(\mathrm{r}=0.82)$, i.e. the degree of airway obstruction. Open symbols: bronchodilation; closed symbols: obstruction; squares: adults; circles: children. Raw*: model estimated airway resistance; $R$ aw,pleth: plethysmographic airway resistance.

\section{Discussion}

This study suggests that DuBois' model may be applied to the respiratory system of asthmatic children after bronchodilation, normal adults or adults with incipient or moderate airway obstruction. In contrast, the coefficients of DuBois' model cannot be reliably estimated in asthmatic children with more severe obstruction.

In adults, the mean value of $R$ aw,pleth and $R$ aw* were not statistically different either before or after bronchodilation, and neither was the average drop in airway resistance, which indicates that the parameter estimation is able to describe the effect of bronchodilation in this study group. However, the model may not be realistic enough for accurate quantitation of individual responses. Also, the differences in measuring conditions may account for some discrepancies between changes in these two estimates of Raw. Raw* and Raw,pleth cannot be measured simultaneously and are, therefore, subjected to the spontaneous variation resulting from lung volume history and bronchomotor tone. Moreover, Raw* and Raw,pleth are measured at different frequencies and under different conditions of breathing pattern and airway flow. The panting manoeuvre produces larger flow, hence larger resistance value, than quiet breathing, but this is probably cancelled by the fact that panting also increases the glottic aperture [11].

When measuring transfer respiratory impedance, some metrological error occurs because of the parallel arrangement of the flowmeter and the upper airway wall, as described with the head generator technique [12, 13]. The error on flow may be significant with transmural pressure drop across the upper airway wall, e.g. during nasal breathing $[7,14,15]$, but is probably minimal during mouth breathing through a low impedance flowmeter at relatively low frequency. The advantage of using higher frequencies to include the antiresonant peak [4] could, thus, be limited by the upper airway wall shunting of flow.

No change in airway inertance was found after bronchodilator in the adult group, and this confirms our previous finding for respiratory inertance obtained with

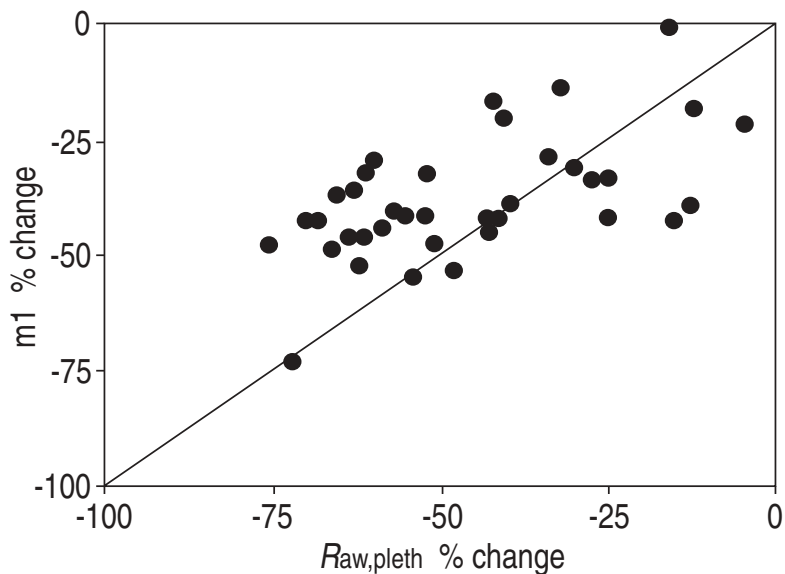

Fig. 5. - Significant correlation $(r=0.57 ; \mathrm{p}<0.005)$ between changes induced by bronchodilation on Raw,pleth and $\mathrm{m} 1$, which is almost equal to the respiratory resistance at zero frequency (see Equation (8)). The identity line is shown. Raw,pleth: plethysmographic airway resistance.

the head generator technique [8]. This is not surprising, since Iaw is mainly related to the dimensions of the trachea, which contributes little to the bronchomotor response.

More interestingly, we found that tissue impedance parameters contributed to the response to bronchodilation, with a significant increase in respiratory compliance and decrease in tissue resistance. The interpretation of respiratory impedance data may be complicated by the viscoelastic properties of the chest wall, which explain marked negative frequency dependence [16]. However, it may reasonably be assumed that the bronchodilator affects only the lung. The mechanical properties of lung tissues may be modelled by a viscoelastic compartment with two parameters: a tissue viscance that accounts for the negative frequency dependence of lung resistance, and an effective elastance [17]. The Newtonian component to lung tissue resistance suggested by measurements of pulmonary impedance in adult humans [18] has not been supported by further studies in open-chest dogs and isolated dog lungs [19]. The increase in lung tissue viscance and elastance by methacholine or histamine has been demonstrated by a number of studies both of lung [20-22] and respiratory impedance [23, 24]. These changes are best measured at low frequency, because of the strong frequency dependence of lung tissue viscance and elastance below a few $\mathrm{Hz}$, and they are thought to be related to the lung tissue response associated with bronchoconstriction. Thus, the changes in $R \mathrm{t}$ and $C \mathrm{t}$ observed after bronchodilation in the present study may well express reversal of lung parenchymal constriction. An alternative - or complementary - explanation for these changes may be the reduced effect of airway wall compliance, and/or the more homogenous distribution of ventilation within the lung, although the regional inhomogeneity of mechanical time constants may be difficult to detect from model analysis [25].

In children with marked airway obstruction, $R$ aw* was significantly underestimated compared with $R$ aw,pleth. Also, the clear change induced by BD on Raw,pleth did not show on $R$ aw*, in contrast to the significant correlation between changes in Raw,pleth and in $\mathrm{m} 1$ - which 
represents mostly the total respiratory resistance at zero frequency (Equation (8)) - showing reasonably good agreement between plethysmographic and transfer impedance methods in evaluating the magnitude of the response to bronchodilation. This, together with the strong correlation shown in figure 4 , indicates that the discordance between $R$ aw* and Raw,pleth in the obstructive children reflects the failure to extract the accurate value of airway resistance from the model, provided there is no major flaw in estimating $C \mathrm{~g}$. It has previously been shown that the accurate separation of airway and tissue impedances in normal adults was also dependent on accuracy of $C \mathrm{~g}$ determination [4]. The determination of $\mathrm{TGV}$, on which was based the calculation of $C \mathrm{~g}$, may be subjected to error in the presence of significant airway obstruction, and this may lead to inaccurate determination of airway and tissue impedance. In order to evaluate the possible contribution of erroneous estimation of $\mathrm{TGV}$, we recalculated airway and tissue parameters using $C$ g, respectively, 25 and $50 \%$ higher and lower than that measured, in two children with airway obstruction (table 3). It may be seen that the effect of $25 \%$ variations in $C \mathrm{~g}$ is generally small, except for Iaw in subject No. 2. Fifty percent variations in $C \mathrm{~g}$ are associated with more significant errors, but such under- or overestimation of $C \mathrm{~g}$ are unlikely to be encountered in the population described here.

Finally, the possibility of deriving airways and tissue properties from $\mathrm{Zrs}$,tr data has been demonstrated mainly in healthy adults $[3,4]$. When studying patients with airway obstruction, YING et al. [26] observed unrealistic values of Iaw and, occasionally, of $R$ t. Although this could be explained to some extent by airway wall shunting, we wondered if the analysis was reliable during airway obstruction, even if the model was adequate. To answer the question, we numerically generated impedance data corresponding to known sets of coefficients (Equations (1) to (4)) at the frequencies used in the patients. We analysed them in the same way as the experimental data, both with and without added noise. Without noise, we observed that, as mentioned in the Methods section, the analysis could provide three different solutions. This was seen to be systematically the case when $R$ aw or $C \mathrm{~g}$ were large, or when $I \mathrm{aw}, R \mathrm{t}$ or $C \mathrm{t}$ were low. For reasonable values of $I_{\mathrm{aw}}\left(2 \mathrm{~Pa} \cdot \mathrm{s}^{2} \cdot \mathrm{L}^{-1}\right), R_{\mathrm{t}}\left(2 \mathrm{hPa} \cdot \mathrm{s} \cdot \mathrm{L}^{-1}\right)$, $C \mathrm{t}\left(20 \mathrm{~mL} \cdot \mathrm{hPa}^{-1}\right)$ and $C \mathrm{~g}\left(2 \mathrm{~mL} \cdot \mathrm{hPa}^{-1}\right)$ in children, a triple solution was always seen when $R$ aw exceeded 6.3 $\mathrm{hPa} \cdot \mathrm{s} \cdot \mathrm{L}^{-1}$.
Table 4. - Example of multiple solutions to noise-free transfer impedance data

\begin{tabular}{lcccc}
\hline & $\begin{array}{c}R \text { aw } \\
\mathrm{hPa} \cdot \mathrm{s} \cdot \mathrm{L}^{-1}\end{array}$ & $\begin{array}{c}I \mathrm{aw} \\
\mathrm{Pa} \cdot \mathrm{s}^{2} \cdot \mathrm{L}^{-1}\end{array}$ & $\begin{array}{c}R \mathrm{t} \\
\mathrm{hPa} \cdot \mathrm{s} \cdot \mathrm{L}^{-1}\end{array}$ & $\begin{array}{c}C \mathrm{t} \\
\mathrm{mL} \cdot \mathrm{hPa}-1\end{array}$ \\
\hline Solution 1 & 3.4 & 0.56 & 7.1 & 20.0 \\
Solution 2 & 8.0 & 2.00 & 2.0 & 20.0 \\
Solution 3 & 8.3 & 2.35 & 1.7 & 20.0 \\
\hline
\end{tabular}

For abbreviations see heading to table 2 .

An example is shown in table 4. In this example, the second solution corresponds to the values used for computing Zrs,tr. Whilst the first solution may be discarded as unrealistic, there is no way to choose between the two others. In our study, all four determinations with three solutions were observed during obstruction and in three determinations, Raw,pleth was above $6 \mathrm{hPa} \cdot \mathrm{s} \cdot \mathrm{L}^{-1}$, which is in agreement with the numerical simulation. As mentioned before, the corresponding data were discarded. When adding a random noise with a reasonable amplitude ( $\pm 5 \%$ of the mean impedance modulus) to the real and imaginary parts of the generated impedance data, a triple solution was not always found when $R$ aw was above the noise-free resistance threshold. For instance, with $R$ aw $=8 \mathrm{hPa} \cdot \mathrm{s} \cdot \mathrm{L}^{-1}$ and the other coefficients as above, it was only the case in about $50 \%$ of the instances. More interestingly, in the other $50 \%$, the unique solution was frequently unrealistic with, seemingly, most of Raw shifted to $R$ t, and a low $I$ aw. In that example, with 1,000 trials, $R$ aw averaged $3.24 \pm 0.26 \mathrm{hPa} \cdot \mathrm{s} \cdot \mathrm{L}^{-1}, R \mathrm{t} 7.30 \pm 0.36$ $\mathrm{hPa} \cdot \mathrm{s} \cdot \mathrm{L}^{-1}$ and Iaw $0.587 \pm 0.014 \mathrm{~Pa} \cdot \mathrm{s}^{2} \cdot \mathrm{L}^{-1}$. As shown in figure $6 \mathrm{a}$, the larger the actual Raw, the more it is underestimated, so that the computed Raw may decrease when the actual one increases. The results of these computer simulations (fig. 6) are in close agreement with the clinical data in children. This phenomenon may, thus, explain the underestimation of $R \mathrm{aw}^{*}$, the large $R \mathrm{t}$ and low Iaw found in our asthmatic children before bronchodilation.

Figure $6 \mathrm{~b}$ also shows that the noise-related variability of $R$ aw* depends very much upon the degree of airway obstruction. The confidence interval (1.64 SD), expressed as a percentage of the mean, increases from about 5 to $56 \%$ when $R$ aw increases from 4 to $7 \mathrm{hPa} \cdot \mathrm{s} \cdot \mathrm{L}^{-1}$; it decreases afterwards, so that, for $R$ aw $=10 \mathrm{hPa} \cdot \mathrm{s} \cdot \mathrm{L}^{-1}$, $R_{\text {aw* }}{ }^{*}$ is strongly underestimated, but with little variability. For the same level of noise on the impedance

Table 3. - Effect of using different gas compressibilities ( $\left.C_{g s}\right)$ on airway and tissue parameter estimation in two children with airway obstruction

\begin{tabular}{|c|c|c|c|c|c|c|c|c|}
\hline & \multicolumn{4}{|c|}{ Subject No. 1} & \multicolumn{4}{|c|}{ Subject No. 2} \\
\hline & $\begin{array}{c}R \text { aw } \\
\mathrm{hPa} \cdot \mathrm{s} \cdot \mathrm{L}^{-1}\end{array}$ & $\begin{array}{c}I \text { aw } \\
\mathrm{Pa} \cdot \mathrm{s}^{2} \cdot \mathrm{L}^{-1}\end{array}$ & $\begin{array}{c}R \mathrm{t} \\
\mathrm{hPa} \cdot \mathrm{s} \cdot \mathrm{L}^{-1}\end{array}$ & $\begin{array}{c}C \mathrm{t} \\
\mathrm{mL} \cdot \mathrm{hPa}^{-1}\end{array}$ & $\begin{array}{c}R \text { aw } \\
\mathrm{hPa} \cdot \mathrm{s} \cdot \mathrm{L}^{-1}\end{array}$ & $\begin{array}{c}\mathrm{Iaw} \\
\mathrm{Pa} \cdot \mathrm{s}^{2} \cdot \mathrm{L}^{-1}\end{array}$ & $\begin{array}{c}R \mathrm{t} \\
\mathrm{hPa} \cdot \mathrm{s} \cdot \mathrm{L}^{-1}\end{array}$ & $\begin{array}{c}C \mathrm{t} \\
\mathrm{mL} \cdot \mathrm{hPa}^{-1}\end{array}$ \\
\hline $\mathrm{Cg}-50 \%$ & 5.8 & 3.4 & 3.0 & 23 & 1.0 & 0.6 & 18.7 & 17 \\
\hline $\mathrm{Cg}-25 \%$ & 6.3 & 2.9 & 2.2 & 23 & 0.7 & 3.0 & 18.9 & 17 \\
\hline $\mathrm{Cg}$ & 6.6 & 2.7 & 1.9 & 23 & 0.6 & 0.3 & 19.1 & 17 \\
\hline $\mathrm{Cg}+25 \%$ & 6.6 & 2.3 & 1.7 & 23 & 0.5 & 0.2 & 19.2 & 17 \\
\hline $\mathrm{Cg}+50 \%$ & 3.0 & 0.6 & 5.6 & 23 & 0.4 & 0.2 & 19.3 & 17 \\
\hline
\end{tabular}

For abbreviations see heading to table 2 . 

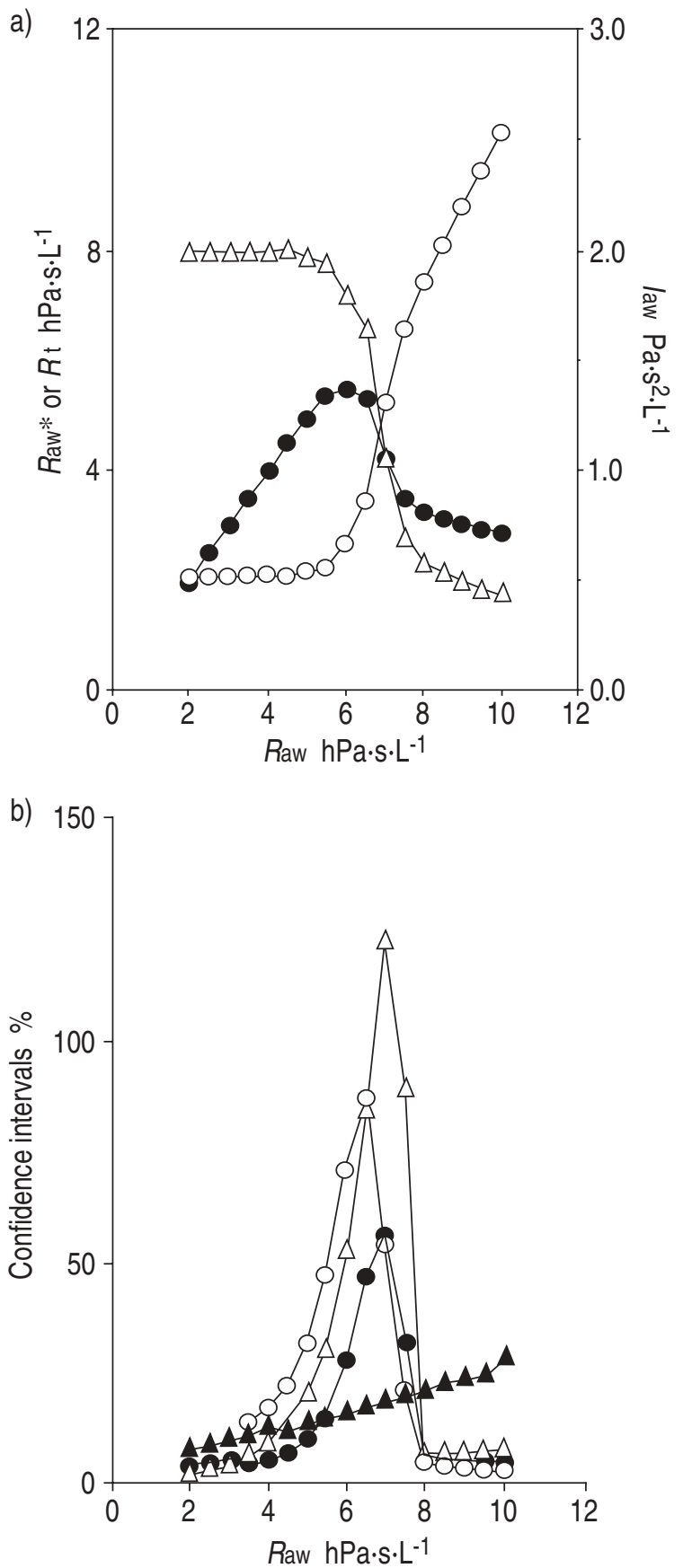

Fig. 6. - Computer simulation. a) Mean of $R a w^{*}, R t$ and Iaw computed from Zrs,tr when the solution is unique, as a function of actual Raw. The data are obtained from 1,000 trials at each value of Raw, with a noise corresponding to $\pm 5 \%$ of the mean impedance modulus. The other parameters have been assigned the following values: Iaw $=2$ $\mathrm{Pa} \cdot \mathrm{s}^{2} \cdot \mathrm{L}^{-1} ; R \mathrm{t}=2 \mathrm{hPa} \cdot \mathrm{s} \cdot \mathrm{L}^{-1} ; C \mathrm{t}=20 \mathrm{~mL} \cdot \mathrm{hPa}^{-1}$; and $C \mathrm{~g}=2 \mathrm{~mL} \cdot \mathrm{hPa}^{-1}$. Raw* is similar to the actual Raw when the latter is between 1 and $6 \mathrm{hPa} \cdot \mathrm{s} \cdot \mathrm{L}^{-1}$, and the estimations of Iaw and $R \mathrm{t}$ are correct. At and above $7 \mathrm{hPa} \cdot \mathrm{s} \cdot \mathrm{L}^{-1}$, $R$ aw* becomes underestimated, $R$ t increases and $I$ aw decreases. b) The confidence intervals of all parameters except $C \mathrm{t}$ show peak distribution at an actual Raw of $7 \mathrm{hPa} \cdot \mathrm{s} \cdot \mathrm{L}^{-1}$. Above and below this threshold, the confidence intervals are much smaller for all parameters. The determination of Raw* may, thus, be considerably underestimated with actual $R$ aw $>7 \mathrm{hPa} \cdot \mathrm{s} \cdot \mathrm{L}^{-1}$; however, with very small statistical error. $C \mathrm{t}$, which is directly derived from Equation (7), shows uniform increase in confidence interval. Raw*: model estimated airway resistance; $R$ t: tissue resistance; Iaw: airway inertance; Zrs,tr: transfer respiratory impedance; Raw: airway resistance; $C \mathrm{t}$ : tissue compliance; $C \mathrm{~g}$ : pulmonary

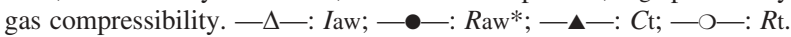

data, the confidence intervals of $I$ aw and $R \mathrm{t}$ vary similarly with the degree of airway obstruction (fig. 6b), being largest when $R$ aw is close to $7 \mathrm{hPa} \cdot \mathrm{s} \cdot \mathrm{L}^{-1}$. In contrast, the noise-related variability of $C$ t, which is obtained directly from the parameter $\mathrm{m} 0$ (Equation (7)), increases monotonously with the degree of obstruction; this increase may, in part, be due to that of the impedance modulus, of which the amplitude of the noise was kept a fixed percentage. One should stress that the confidence intervals of $R$ aw, Iaw and $R \mathrm{t}$ shown in figure $6 \mathrm{~b}$ only pertain to the situation where the solution to Equation (13) is unique. Much larger differences may occur between multiple solutions, as shown in table 4.

We conclude that the analysis of transfer respiratory impedance in terms of airways and tissue properties, according to this simplified variant of DuBois' model is unreliable in children with airways resistance above about $6 \mathrm{hPa} \cdot \mathrm{s} \cdot \mathrm{L}^{-1}$. Computer simulation suggests that this threshold would increase to $10 \mathrm{hPa} \cdot \mathrm{s} \cdot \mathrm{L}^{-1}$ if airways inertance was raised to about $5 \mathrm{~Pa} \cdot \mathrm{s}^{2} \cdot \mathrm{L}^{-1}$. This could easily be achieved by placing an additional inertance at the airway opening. On the other hand, the use of a larger frequency spectrum to include the antiresonant peak should theoretically improve the parameter estimation in the moderately obstructed subjects [4]. However, both solutions have the potential drawback of increasing the errors related to the shunt impedance of upper airway walls. Further work is needed to assess these possibilities.

Acknowledgements: The authors thank C. Choné, G. Colin, B. Delorme, F. Fortin, O. Lacome and S. Méline for skilled technical assistance and C. Creusat for typing the manuscript. N. Bouaziz was supported by a grant from l'Institut Electricité Santé'.

\section{References}

1. Peslin R, Jardin P, Duvivier C, Bégin P. In-phase rejection requirements for measuring respiratory input impedance. J Appl Physiol: Respirat Environ Exercise Physiol 1984; 56: 804-809.

2. Dubois AB, Brody AW, Lewis DH, Burgess BF. Oscillation mechanics of lungs and chest in man. J Appl Physiol 1956; 8: 587-594.

3. Peslin R, Papon J, Duvivier C, Richalet J. Frequency response of the chest: modeling and parameter estimation. J Appl Physiol 1975; 39: 523-534.

4. Lutchen KR, Everett JR, Jackson AC. Impact of frequency range and input impedance on airway-tissue separation implied from transfer impedance. J Appl Physiol 1993; 74: 1089-1099.

5. Lutchen KR, Jackson AC. Reliability of parameter estimates from models applied to respiratory impedance data. J Appl Physiol 1987; 62: 403-413.

6. Rotger M, Peslin R, Oostveen E, Gallina C. Confidence intervals of respiratory mechanical properties derived from transfer impedance. J Appl Physiol 1991; 70: 2432-2438.

7. Marchal F, Colin G, Chalon B, Duvivier C, Crance JP, Peslin R. Transfer respiratory impedance and thoracic gas volume to estimate airway and tissue impedance in infants. Eur Respir Rev 1994; 4: 159-164.

8. Marchal F, Mazurek H, Habib M, Duvivier C, Derelle 
J, Peslin R. Input respiratory impedance to estimate airway hyperreactivity in children: standard method versus head generator. Eur Respir J 1994; 7: 601-607.

9. Peslin R, Gallina C, Rotger M. Methodological factors in the variability of lung volume and specific airway resistance measured by body plethysmography. Bull Eur Physiopathol Respir 1987; 23: 323-327.

10. Bland JM, Altman DG. Statistical methods for assessing agreement between two methods of clinical measurement. Lancet 1986; i: 307-310.

11. Stanescu DC, Patiijn J, Clément J, Van De Woestijne KP. Glottis opening and airway resistance. J Appl Physiol 1972; 32: 460-466.

12. Peslin R, Duvivier C, Didelon J, Gallina C. Respiratory impedance measured with head generator to minimize upper airway shunt. J Appl Physiol 1985; 59: 1790-1795.

13. Van De Woestijne KP, Cauberghs M. The upper airway artefact. Eur Respir Rev 1991; 1: 139.

14. Marchal F, Peslin R, Duvivier C, Gallina C, Crance JP. Measurement of ventilatory mechanical impedance in infants using a head pressure generator. Pediatr Pulmonol 1989; 7: 209-216.

15. Oostveen E, Zwart A, Peslin R, Duvivier C. Respiratory transfer impedance and derived mechanical properties of conscious rats. J Appl Physiol 1992; 73: 1598-1607.

16. Hantos Z, Daroczy B, Suki B, Galgoczy G, Csendes T. Forced oscillatory impedance of the respiratory system at low frequencies. J Appl Physiol 1986; 60: 123-132.

17. Hildebrandt J. Pressure-volume data of cat lung interpreted by a plastic, linear viscoelastic model. J Appl Physiol 1970; 28: 365-372.
18. Suki B, Peslin R, Duvivier C, Farré R. Lung impedance in healthy humans measured by forced oscillations from 0.01 to $0.1 \mathrm{~Hz}$. J Appl Physiol 1989; 67: 16231629.

19. Petak F, Hantos Z, Adamicza A, Daroczy B. Partitioning of pulmonary impedance: modeling $v s$ alveolar capsule approach. J Appl Physiol 1993; 75: 513-521.

20. Ludwig MS, Robatto FM, Sly PD, Browman M, Bates JHT, Romero PV. Histamine-induced constriction of canine peripheral lung: an airway or tissue response? $J$ Appl Physiol 1991; 71: 287-293.

21. Romero PV, Robatto FM, Simard S, Ludwig MS. Lung tissue behavior during methacholine challenge in rabbits in vivo. J Appl Physiol 1992; 73: 207-212.

22. Tepper R, Sato J, Suki B, Martin JG, Bates JHT. Lowfrequency pulmonary impedance in rabbits and its response to inhaled methacholine. J Appl Physiol 1992; 73: 290-295.

23. Lutchen KR, Jackson AC. Effects of tidal volume and methacholine on low-frequency total respiratory impedance in dogs. J Appl Physiol 1990; 68: 2128-2138.

24. Lauzon AM, Dechman G, Bates JHT. Time course of respiratory mechanics during histamine challenge in the dog. J Appl Physiol 1992; 73: 2643-2647.

25. Hantos Z, Daroczy B, Suki B, Nagy S, Fredberg JJ. Input impedance and peripheral inhomogeneity of dog lungs. J Appl Physiol 1992; 72: 168-178.

26. Ying Y, Peslin R, Duvivier C, Gallina C, Felicio da Silva J. Respiratory input and transfer mechanical impedances in patients with chronic obstructive pulmonary disease. Eur Respir J 1990; 3: 1186-1192. 